\title{
Willingness to Pay for Oral Health Care for 350 Users of Public Dental Offices in Abidjan in Côte d'Ivoire
}

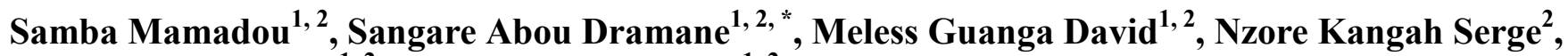 \\ Guinan Jean-Claude ${ }^{1,2}$, Bakayoko-Ly Ramata ${ }^{1,2}$ \\ ${ }^{1}$ Department of Public Health, UFR Odonto-Stomatology, University FHB, Abidjan, Côte d'Ivoire \\ ${ }^{2}$ Laboratory of Public Health and Medicinal Plants, UFR Odonto-Stomatology, University FHB, Abidjan, Côte d'Ivoire
}

Email address:

sangare_aboudramane@yahoo.fr (S. A. Dramane)

${ }^{*}$ Corresponding author

\section{To cite this article:}

Samba Mamadou, Sangare Abou Dramane, Meless Guanga David, Nzore Kangah Serge, Guinan Jean-Claude, Bakayoko-Ly Ramata. Willingness to Pay for Oral Health Care for 350 Users of Public Dental Offices in Abidjan in Côte d'Ivoire. International Journal of Health Economics and Policy. Vol. 4, No. 3, 2019, pp. 89-94. doi: 10.11648/j.hep.20190403.14

Received: August 10, 2019; Accepted: September 5, 2019; Published: September 19, 2019

\begin{abstract}
In Côte d'Ivoire, the financial difficulties experienced by the population represent obstacles to the consumption of oral health care. Thus, insurance mechanisms based on the principle of cost sharing are recommended to improve financial accessibility to this care. The cross-sectional study was conducted with users of three public dental practices in the city of Abidjan. The data were collected using a questionnaire. The numbers and frequencies related to the modalities of the use of oral health care, as well as the users' perception of their costs were calculated. Also, the willingness of users to pay for oral care has been measured. 350 users participated in the study. More than one third of users $(36 \%)$ felt that the cost of dental services was high. $80.1 \%$ and $57.1 \%$ of respondents reported spending less than $5 \$$ US to honor the cost of oral consultation and the purchase of medicines respectively. $74 \%$ of users were in favor of setting up an insurance system with a willingness to pay less than $10 \$$ US per month. This willingness to pay has been estimated for all users at $2 \$$ US per month. The willingness of populations to contribute to the financing of oral health care has been proven. Achieving universal health coverage based on solidarity requires the establishment of prepayment mechanisms by adjusting the amounts of contributions to each person's ability to pay.
\end{abstract}

Keywords: Oral Health, Affordability, Willingness to Pay, Prepayment, Côte d'Ivoire

\section{Introduction}

Oral health is an integral part of general health and well-being. It is fundamental to breathing, eating, swallowing, talking or even smiling [1]. In the African region, poor oral health affects millions of people. It is a public health problem because of the morbidity of oral diseases and their economic impact on society [2]. Following the "Bamako Initiative" which established the principles of cost recovery for acts in African countries in 1987 [3], the populations of African countries who must now contribute to the financing of their health are faced with certain financial difficulties in accessing care. Thus, in most countries, households see their direct health expenditure increase, while their quality of life and state of well-being deteriorate [1]. This is the case in Côte d'Ivoire where, with a rapidly growing population, a constant decline in people's incomes and insufficient social security coverage, the problem of access to oral health care is acute. These difficulties of access to healthcare are also observed in public health facilities, which are mainly frequented by the population and which are supposed to offer services at a lower cost [4]. To remove this financial barrier to access to oral health care, insurance mechanisms based on the principle of cost sharing are recommended. This raises the problem of the populations' ability to contribute to the financing of care, objectified by their willingness to pay for it. This is a popular approach to evaluating health care benefits [5]. It refers to the maximum amount in monetary terms that an individual would be willing to sacrifice to obtain the benefits of a program, a benefit [6]. The objective of this study, which is part of a process of proposing an appropriate financing mechanism, was to analyze the willingness to pay for oral health 
care for users of public dental practices in Abidjan.

\section{Methods}

\subsection{Type and Area of the Study}

The cross-sectional analytical study focused on the city of Abidjan, the economic capital and main city of Côte d'Ivoire which is a country located in West Africa.

\subsection{Study Population, Selection Criteria, Sample Size}

The study concerned users who attended the dental offices of public institutions of Abobo (North Abidjan), Attecoube (Abidjan center) and Port-Bouët (South Abidjan). The sample of the study was constituted by reasoned choice by the systematic and simultaneous recruitment of the users satisfying the criteria of inclusion in the 3 dental offices during a month. Was included, any user came in consultation during the study period for himself or for a child and who agreed to participate in the study.

\subsection{Data Collection and Variables Studied}

The data were collected using a questionnaire by an interviewer for each dental office during face-to-face interviews with users. It included several variables related to the socio-demographic characteristics of users, their perception of the cost of care and their willingness to pay for it.

\subsection{Data Analysis}

Data analysis and processing were carried out by Excel 2007 and Epi Info version 6 software, and headcount and percentages were calculated. The chi-square test was used to assess the relationship between certain variables of interest with a significance threshold $\alpha=5 \%$.

\section{Results}

\subsection{Socioeconomic Parameters}

Table 1. Distribution of users according to the dental practice attended.

\begin{tabular}{lll}
\hline Dental office & $\mathbf{N}$ & $\mathbf{\%}$ \\
\hline Port-Bouët & 151 & 43,1 \\
Attécoubé & 64 & 18,3 \\
Abobo & 135 & 39,6 \\
Total & 350 & 100,0 \\
\hline
\end{tabular}

\subsection{Costs of Oral Health Care}

Table 4. Estimate of the amount paid for dental care according to the care centre.

\begin{tabular}{|c|c|c|c|c|}
\hline \multirow{3}{*}{ Dental office } & \multicolumn{3}{|c|}{ Amount paid during a consultation (\$ US) } & \multirow{2}{*}{ Total } \\
\hline & $\leq 5$ & $5-10$ & $>10$ & \\
\hline & n (\%) & n (\%) & n (\%) & n (\%) \\
\hline HG Port-Bouët & $150(99.3)$ & $0(0.0)$ & $1(0.7)$ & $151(43.1)$ \\
\hline FS d'Attécoubé & $6(9.4)$ & $35(54.7)$ & $23(35.9)$ & $64(18.3)$ \\
\hline HG d'Abobo & $125(92.6)$ & $6(4.4)$ & $4(3.0)$ & $135(38.6)$ \\
\hline Total & $281(80.3)$ & $41(11.7)$ & $28(8.0)$ & $350(100.0)$ \\
\hline
\end{tabular}

Chi-square $=263.07 \mathrm{ddl}=4 \mathrm{p}=10^{-3}$. 
The difference observed between the amounts paid for a consultation in the different dental offices was statistically significant. The highest rates were charged in Attecoube. The majority of respondents $(80.3 \%)$ reported that they paid an amount less than or equal to 5 \$ US during the consultation with the dental surgeon. The amount disbursed was more than 10 \$ US for only $8 \%$ of the respondents.

Table 5. Average cost of a pharmaceutical prescription.

\begin{tabular}{|c|c|c|c|c|}
\hline \multirow{3}{*}{ Dental office } & \multicolumn{3}{|c|}{ Average cost (\$ US) } & \multirow{2}{*}{ Total } \\
\hline & $\leq 5$ & $5-10$ & $>10$ & \\
\hline & n (\%) & n (\%) & n (\%) & n (\%) \\
\hline HG Port-Bouët & $55(48.7)$ & $37(32.7)$ & $21(18.6)$ & $113(41.4)$ \\
\hline F S d'Attecoube & $40(71.4)$ & $5(8.9)$ & $11(19.7)$ & $56(20.5)$ \\
\hline HG d'Abobo & $61(58.7)$ & $30(28.8)$ & $13(12.5)$ & $104(38.1)$ \\
\hline Total & $156(57.1)$ & $72(26.4)$ & $45(16.5)$ & $273(100.0)$ \\
\hline
\end{tabular}

Chi-square $=13.54 \mathrm{ddl}=4 \mathrm{p}=0.0089$.

The difference observed in the cost of prescriptions dispensed in the 3 dental offices was statistically significant. This cost was high in Attecoube and Port-Bouët. For more than half $(57.1 \%)$ of the users of the 3 dental offices, the cost of the prescription was less than or equal to $5 \$$ US.

\subsection{Financing of Oral Care by Users}

Table 6. Inability of users to pay for oral health care by dental office visited.

\begin{tabular}{|c|c|c|c|}
\hline \multirow{3}{*}{ Dental office } & \multicolumn{2}{|c|}{ Inability to pay for dental care } & \multirow{2}{*}{ Total } \\
\hline & Yes & No & \\
\hline & n (\%) & n (\%) & n (\%) \\
\hline HG Port-Bouët & $44(27.5)$ & $107(72.5)$ & $142(43.1)$ \\
\hline F S d'Attécoubé & $33(51.6)$ & $31(48.4)$ & $64(18.3)$ \\
\hline HG d'Abobo & $41(30.4)$ & 94 (69.6) & $135(38.6)$ \\
\hline Total & $118(33.7)$ & $232(66.3)$ & $350(100.0)$ \\
\hline
\end{tabular}

Inability to pay for oral health care was related to the type of health facility attended. Users of the Attecoube dental office reported the most inability to pay for this care. Overall, one-third of all respondents $(33.7 \%)$ said they were often unable to pay for dental care.

Table 7. Willingness to pay for oral health care for users.

\begin{tabular}{lll}
\hline Willingness to pay for oral health & Number & $\%$ \\
\hline Yes & 258 & 74.0 \\
No & 92 & 26.0 \\
Total & 350 & 100.0 \\
\hline
\end{tabular}

$74 \%$ of dental office users were willing to pay money for oral health care.

Table 8. Monthly amount to be paid for oral care desired by users.

\begin{tabular}{lllll}
\hline Monthly investment (\$ US) & Number & \% & Average & Standard deviation \\
\hline$[100-1000]$ & 121 & 50,0 & 712 & 309 \\
{$[1500-25000]$} & 121 & 50,0 & 4.347 & - \\
Total & 242 & 100,0 & 3.447 \\
\hline
\end{tabular}

Whatever the class obtained from the amount declared by the respondents, the average monthly investment was less than $10 \$$ US. The average amount that can be tolerated by all is 1.45 \$ US, estimated at 2 \$ US per month taking into account the standard deviation.

\section{Discussion}

In the health sector, the function of demand is difficult to measure by direct observation of the behaviour of economic agents because of the financing method and the existence of externalities [5]. To overcome this difficulty, having a perfect knowledge of the health program, the contingent valuation method is used by having the individual declare the amount he is willing to sacrifice in order to benefit from this property. This value is called "willingness to pay". The assessment of willingness to pay while giving an indication to decision-makers presents biases in the sense that there is a difference between the actual consumption of a good and a hypothetical consumption. The question of the stability of individual preferences remains therefore posed [7] and leads one to take the value of willingness to pay with great caution. In spite of this limitation, the methodology used in our study with as a tool the questionnaire and method of collecting face-to-face interviews, are consistent with those used in most studies to assess willingness to pay [8].

In the study sample, more than half of the respondents $(52.2 \%)$ were women (table 2$)$. This suggests that women are more concerned about their oral health than men. Also, the proportion of young people between 15 and 24 years of age was the highest (34\%). This proportion corroborates the data of the National Institute of Statistics [9] of Côte d'Ivoire from the latest general census highlighting the youthfulness of the Ivorian population. Employees represented $13.7 \%$ of the sample. The majority of respondents stated that they do not have health coverage, which considerably limits their financial accessibility to oral health care. In many studies on willingness to pay, female gender, young age and high educational attainment are associated with high willingness to pay $[8 ; 10]$. However, in Finland in 2002, high income and male gender were the main factors associated with a good ability to pay for dental care [11]. 
With regard to users' perception of the cost of oral health care provided in public dental offices, more than half of the respondents $(58.6 \%)$ considered them affordable. However, for $36.8 \%$ of these people, they were high (table 3 ). The direct costs incurred by oral health care are related to the cost of consultations, the dental procedure and/or the medical prescription accompanying the procedure. These average direct costs were less than 10 \$ US (tables 4, 5) for the majority of respondents (service costs less than or equal to 5 $\$$ US for $80 \%$ of users; prescription costs less than or equal to 5 \$ US for $57.1 \%$ of users). For users residing outside the municipality of the health centre, the indirect costs related to transport are less than 5 \$ US. Thus, the average cost of using the oral health service of a public health facility in Abidjan would be less than 15 \$ US. The average cost of a medical consultation in a community-based health centre in Abidjan was estimated at 8.8 \$ US in 2003 [12]. Under these conditions, the average cost of using oral health services would be higher than that estimated for general medical care. This observation is confirmed by the work of Escalon [13], which in 1999 observed a lower cost of care than Soumahoro in a study carried out in the community-based health facilities in Abidjan. This cost was 6.39 \$ US. The high cost of oral health care is one of the main reasons why people in Africa often give up health care [14-16]. Samba et al. [17] through a study on the waiver of oral health care in Abidjan in 2003 involving 400 heads of household, showed that $20 \%$ of heads of household waived oral health care. For one-third of these people, the cost of dental procedures is high, which explains their financial inability to cope. These results confirm that the lack of financial resources hinders access to oral health care. The financial obstacle is all the more important because there is no social protection system in these countries. In Côte d'Ivoire, only about $6 \%$ of the population has health insurance [18] and dental care is not always well reimbursed. This result is confirmed by Soumahoro's study [12] which found a satisfaction rate of $66.22 \%$.

In general, the acceptability of the cost of care can be influenced by several factors including the ability of users to pay for it and its perception of their quality. In our study, the evaluation of the ability to pay showed that more than a third of the respondents $(33.7 \%)$ were often unable to pay for oral health care (table 6). Difficulties of affordability are observed among some patients in developing countries. Either they do not have the means (health coverage) to meet the cost of care, or they consider that consultations are too costly in terms of their ability to finance. In these countries, the direct payment of care by users comes to the rescue of failures of state funding. Indeed, states no longer manage to ensure the goal of free care posted in the aftermath of independence [19]. As social insurance was not yet fully effective in Côte d'Ivoire, $74 \%$ of respondents were willing to pay a certain amount to benefit from oral health care (table 7). Although this is an expressed desire, the value of the willingness to pay was very variable and related to the heterogeneity of the contributors' ability to pay. Two classes were distinguished: those who could pay between $0.2 \$$ US and 2 \$ US with an average of 1.45 \$ US and a standard deviation of 0.62 \$ US and those who were willing to pay an amount between 3 \$ US and 50 $\$$ US with an average of 8.70 \$ US and a standard deviation of 6.90 \$ US (table 8). A monthly amount of 2 \$ US was therefore retained as the amount to be paid to benefit from a health insurance taking into account oral health care. Indeed, according to Aballea, the ability to pay for care has two thresholds: below a low or very low level of price, the ability to pay is real for most of the population. Above a relatively high price level, a large part of the population is unable to pay for care [20]. The acceptable threshold in our study is therefore around 2 \$ US per month, an amount equivalent to the contribution per person instituted by the Government to benefit from health coverage in Côte d'Ivoire. The willingness to pay also varies according to the type of care and can be used as a method of revealing preferences. While this avenue was not explored in our study, in Tanzania it was shown that people were more willing to pay for conservative care (3.5 \$ US) than for dental extractions (2.5 \$ US). For both types of care, the amounts that people were willing to pay were less than the amounts charged [10]. In Thailand, on the other hand, the willingness of parents to pay for curative or preventive care for their children was almost identical. A strong correlation was observed between willingness to pay and parents' high incomes [21].

Also in our study, the interest of dental office users in a social protection mechanism remains proven $(74.0 \%)$. The usefulness of such a system, based on the principle of cost sharing, is to protect populations from financial risk so that they are not confronted with catastrophic health expenditures. Indeed, according to the World Health Organization, each year, about 44 million households worldwide, or more than 150 million people, face catastrophic expenditures and some 20 million households (more than 100 million people) fall into poverty because of the cost of health services [22]. For sufficient mobilization of financial resources for health, it is therefore necessary for the whole population to join the social protection system. In return, the health system must provide quality services so that everyone is satisfied with the services they receive for what they pay.

\section{Conclusion}

The determination of the willingness to pay contributes to the economic rationality in that it allows to determine the rest dependent on the State and thus better guide investments without the participation of the population in financing its health is a burden for her. This study showed that in the face of financial problems related to access to care, the population was willing to pay for the management of their oral health. This measure of willingness to pay could be used in developing countries to improve the conditions for people's participation in financing their health. Thus, achieving universal health coverage as advocated by WHO will become a reality. 


\section{Authors Contributions}

SM contributed to the conception of the study, the analysis and the interpretation of data. He gave final approval of the version to be published; agreed to be accountable for all aspects of the work in ensuring that questions related to the accuracy or integrity of any part of the work are appropriately investigated and resolved.

SAD contributed to the conception of the study, the analysis and the interpretation of data. He gave final approval of the version to be published; agreed to be accountable for all aspects of the work in ensuring that questions related to the accuracy or integrity of any part of the work are appropriately investigated and resolved.

MGD contributed to the conception of the study, the analysis and the interpretation of data. He gave final approval of the version to be published; agreed to be accountable for all aspects of the work in ensuring that questions related to the accuracy or integrity of any part of the work are appropriately investigated and resolved.

NKS contributed to the conception of the study, the analysis and the interpretation of data. He gave final approval of the version to be published; agreed to be accountable for all aspects of the work in ensuring that questions related to the accuracy or integrity of any part of the work are appropriately investigated and resolved.

GJC contributed to the conception of the study, the analysis and the interpretation of data. He gave final approval of the version to be published; agreed to be accountable for all aspects of the work in ensuring that questions related to the accuracy or integrity of any part of the work are appropriately investigated and resolved.

BLR contributed to the conception of the study, the analysis and the interpretation of data. He gave final approval of the version to be published; agreed to be accountable for all aspects of the work in ensuring that questions related to the accuracy or integrity of any part of the work are appropriately investigated and resolved.

\section{Authors' Statement}

The informed consent of the respondents was obtained prior to their participation in the study. Each study participant was briefed on the study objective and confidentiality was assured for any information provided. Authors declare that they have no competing interest.

\section{References}

[1] Petersen PE, Kwan S. The 7th WHO Global Conference on Health Promotion - towards integration of oral health (Nairobi, Kenya 2009). Community Dent Health. 2010, 27 : 129-135.

[2] World Health Organization-Africa Regional Office. Regional Strategy for Oral Health 2016-2025: Combating oral diseases as part of the fight against non-communicable diseases. AFR/RC66/6 AUGUST 2016.
[3] World Health Organization. The Bamako Initiative: Some General Principles, Brazzaville 1989.

[4] Samba M, Guinan J C, Da-Danho V T, Nzore K S, Maroua G T, Manie S O, Ane E H, Bakayoko-Ly R. Study of the attendance at the dental care centre of the odonto-Stomatology UFR of Abidjan. Rev. Col Odonto-Stomatol. Afr. Chir. Maxillo-fac. 2002; 9 (4): 44-48.

[5] Hanley N, Ryan M, Wright R. Estimating the monetary value of health care: lessons from environmental economics. Health Econ. 2003; 12 (1): 3-16.

[6] Olsen J, Smith R. Theory versus practice: a review of «willingness to pay» in health and health care. Health Econ 2001; 10: 39.52 .

[7] Carlsson F, Martinsson P. Do hypothetical and actual marginal willingness to pay differ in choice experiments? I Environ Econom Management 2001; 41: 179-92.

[8] Tan SHX, Vernazza CR, Nair R. Critical review of willingness to pay for clinical oral health interventions. J Dent. 2017; 64: $1-12$.

[9] National Institute of Statistics. First final results of the General Population and Housing Census (RGPH-98). Abidjan RCI, 2000.

[10] Nyamuryekunge KK, Lahti SM, Tuominen RJ. Patients' willingness to pay for dental services in a population with limited restorative services. Community Dent Health. 2018; 35 (3): $167-172$.

[11] Widström E, Seppälä T. Willingness and ability to pay for unexpected dental expenses by Finnish adults. BMC Oral Health. 2012; 12: 35.

[12] Soumahoro L. Evaluation of the economic accessibility of care in two community-based health centres. Thesis in Medicine, UFR of Medical Sciences, Cocody University, Abidjan 2003.

[13] Escalon E, Barbe T, Ortiz C, et al. what to expect from private non-profit management? The example of the FSU-COM in Abidjan. In Brunet J., Jailly, eds. Health in capitals, the dynamics of health systems in West African capitals. Abidjan: CEDA, 1999: 241-259.

[14] Samba M, Kouadio NGA, Guinan JC, et al. The renunciation of oral health care in Abidjan. Rev Col Odonto-Stomatol Afr Chir Maxillo-fac. 2003; 10: 52-57.

[15] Lo CM, Cissé D, Faye D et al. Factors associated with the abandonment of oral health care in Senegal. Lettre de Santé Publique bucco-dentaire. 2010; 1: 8-11.

[16] Sangaré AD, Samba M, Guinan JC et al. Socio demographic factors associated with renunciation to oral care in Côte d'Ivoire. MOJ Public Health. 2017; 6 (1): 241-248.

[17] Samba M., Guinan J C., Kouadio N. G. A., Da-Danho V., Bakayoko-Ly R. Oral health care costs in Abidjan. Rev. Col. Odonto-Stomatol. Afr. Chir. Maxillo-fac. 2005; 12: 26-31.

[18] Ministry of Health and AIDS Control - Côte d'Ivoire. National Health Accounts 2013.

[19] Dumoulin J, Kaddar M. Payment for care by users in subSaharan African countries: economic rationality and other subsequent issues. In: Sciences sociales et santé 1993; 11: 81119. 
[20] Aballea P. Is the measurement of household capacity to pay useful for the implementation of community financing of health services? in: CIE, 1992.

[21] Tianviwat S, Chongsuvivatwong V, Birch S. Prevention versus cure: measuring parental preferences for sealants and fillings as treatments for childhood caries in Southern Thailand. Health Policy 2008; 86: 64-71.

[22] World Health Organization. Financing system: how to reduce catastrophic health expenditure; technical summary $\mathrm{N}^{\circ} 2$, $\mathrm{WHO} / \mathrm{EIP} / \mathrm{HSF} / \mathrm{PB} / 05.02$. F; 2005. 